\title{
A Comparison of Self-Report Adult Attachment Measures: How Do They Converge and Diverge?
}

\author{
Lin Shi ${ }^{1{ }^{1 *}, \text { Richard Wampler }}{ }^{2}$, Karen Wampler ${ }^{2}$ \\ ${ }^{1}$ Marriage and Family Therapy Program, School of Family, Consumer, and Nutrition Sciences, \\ Northern Illinois University, DeKalb, IL, 60115, USA \\ ${ }^{2}$ Couple and Family Therapy Program, Department and Human Development and Family Studies, \\ Michigan State University, East Lansing, MI 48823, USA \\ *Corresponding Author: 1shi@niu.edu
}

Copyright $(2013$ Horizon Research Publishing All rights reserved.

\begin{abstract}
Using a sample of 448 undergraduate students the study compared two self-report adult attachment measures: the original three-category Attachment Style Prototype (ASP) and the two-dimension four-category Experiences in Close Relationships (ECR). The distribution of attachment style categories assessed by the two measures differed significantly, and the shifts among the categories were not related solely to the introduction of the fourth category in ECR. However, the two measures were related in meaningful ways, despite differences in conceptualization. The dimensional ECR was a better predictor of the criterion variables, conflict resolution behaviors (measured by Rahim Organizational Conflict Inventory-II), than the ASP. The dimensional ECR is a more sensitive and powerful instrument in the relationship context examined. However, categorical measures provide a broad description of the archetype of the attachment style category.
\end{abstract}

Keywords Adult Attachment, Self-Report Measures, Comparison, Romantic Relationship, Conflict Resolution Behavior

\section{Introduction}

Description of the internal working model of attachment involves the identification of a characteristic attachment style [1], which follows two traditions. One is an interview-based method represented by the Adult Attachment Interview (AAI) [2] that relies on making inferences about attachment in adults, based on the qualities of descriptions of relationships with important adults in childhood. The AAI views attachment from a developmental perspective, seeing attachment as a life-span concept that is relatively stable over time [1]. The other tradition comes from a social and personality psychology approach to adult romantic relationships [1], and typically relies on self-report instruments to determine attachment category. This approach was pioneered by Hazan and Shaver [3]who created the Attachment Style Prototype (ASP)that views romantic relationships as an outgrowth of previous attachment experiences [4]. Although both traditions are grounded in Bowlby's attachment theory and Ainsworth's infant attachment typology, there is evidence that they reflect two different conceptualizations of adult attachment [5].

The vigorous debate between the observational/interview and self-report camps as to which tradition most accurately reflects attachment typology has led to an impression that self-report attachment measures are relatively homogeneous, and, therefore, can be used interchangeably. This impression has been further strengthened by the finding that studies relying on a wide variety of self-report measures for adult attachment classification yield significant predictions of criterion variables. Few studies have incorporated more than one of these self-report measures to compare their relationships with criterion variables.

There is a rich diversity within the self-report tradition. With an increase of interest in the study of romantic relationships through the lens of attachment, numerous self-report adult attachment scales have been developed in the past two decades. Over the years, measures have grown more sophisticated, moving from a single-item categorical instrument [3] to various dimensional measures (e.g., the three-scale, three-category AAS of [6]), and to two-dimensional, four-category measures $([5,7,8])$.

\subsection{Three-Category Self-Report Measures}

The original Hazan and Shaver [3] three-category single-item ASP was widely adopted in the early stage of adult romantic attachment research. However, the ASP was criticized for its assumption that the three attachment styles, Secure, Avoidant, and Anxious/Ambivalent, are mutually exclusive $[6,9,10]$. That is, a respondent might see elements in each paragraph description that somewhat described him/herself. In response, Collins and Read [6] developed a dimensional measure (AAS) by deconstructing Hazan and 
Shaver's three paragraphs into multiple items and establishing three scales through factor analysis. There is a scale to describe the extent to which a person is comfortable with closeness, feels he/she can rely on others, or is anxious or fearful about being abandoned or unloved. Other researchers have made similar improvements in instruments assessing the three-category model [e.g., 11,12].

\subsection{Two-Dimension, Four-Category Self-Report Measures}

In contrast to the three-categorydescription of adult attachment style, Bartholomew [5,7] proposed a two-dimension, four-category model of adult attachment and developed a measure to assess each dimension. They argued that this instrument was consistent with Bowlby's [13] proposal of images of the self and others. A person's image of the self is dichotomized as positive and negative (the self as worthy of love and support vs. not). The image of others is also dichotomized (other people are seen as trustworthy and available vs. unreliable and rejecting). Therefore, four attachment patterns are derived from a combination of the two dimensions: secure (comfortable with intimacy and autonomy), preoccupied (preoccupied with relationships; equivalent to anxious/ambivalent), dismissing (dismissing of intimacy, counter-dependent), and fearful (fearful of intimacy, socially avoidant) [5]. A conceptually similar two-dimension, four-category model with avoidance and approach as the two dimensions and the same/similar category names has also been developed [8]. This newer instrument and the Bartholomew instrument administered to a single sample resulted in a $53 \%$ rate of agreement across the four categories, and a $\chi^{2}$-test indicated a significant difference between the distributions [8, p. 62].

\subsection{Categorical Vs. Dimensional Measures}

The categorical, 3-, and 4-dimensional measures all have been widely used in adult attachment research. A clear conceptual difference between the categorical and dimensional self-report measures is that the categorical approach assumes qualitative differences in internal working models among groups, i.e., that the categories are mutually exclusive, while the dimensional approach assumes that differences occur incrementally and that the definition of a category can be somewhat arbitrary $[6,14]$. It is unclear whether one approach captures the essence of attachment better, or whether they capture various aspects of attachment and are complementary. If the latter is true, then the question becomes "What aspects of relationship functioning does each type of measure capture best?"As Crowell, et al. [15] stated in their review of self-report attachment measures one of the controversies remains after close to three decades of research is whether adult attachment patterns are best conceptualized in categories or in dimensions. Secondly, although self-report adult attachment measures are grounded in Bowlby's attachment theory, confusion remains about whether they measure attachment behaviors that tend to be relatively stable across all attachment relationships, or thoughts, feelings, behavior, and expectations that are somewhat relationship specific or specific to romantic relationships.

\section{Objectives}

When reviewing studies employing a self-report method, it is evident that researchers typically do not justify their choice of adult attachment measure. Given the wide use and wealth of data derived from so many of self-report measures, it is important to understand what these scales really measure before moving any further [16].

The present study compared the ASP [3] three-category model of adult attachment to the two-dimensional, four-category measure, the Experiences in Close Relationships [ECR, 8]. Differences between the ASP and ECR in the distribution of attachment styles by age, length, and status of romantic relationship were examined. Further, the ASP and ECR categories were compared as to how well they predicted conflict resolution behaviors in romantic relationships. The study also examined relationships between the two measures.

There are three reasons to choose these two measures for comparison. First, the three-category (e.g., ASP) and four-category (e.g., ECR) approaches have been widely adopted by researchers. ASP continues to shows its predictive power of numerous relationship variables (i.e., 17,18]. The results of the present study may help evaluate data from previous adult attachment research that used self-report methods. Secondly, the results will allow comparisons between three- and four-category data developed from a single sample, and between categorical [ASP, 3] and dimensional measures [ECR scales, 8]. Finally, the comparison between the original measure and one of the latest self-report measures may illuminate the process of the development of adult attachment research.

\section{Materials and Methods}

\subsection{Participants and Procedures}

The sample for this study included 448 (240 females, 208 males) undergraduate students at a large Southwestern university. Two thirds of the participants were recruited from family science and human development courses that met general educational requirements for the university, and represented a wide range of student majors; the remaining third were recruited from classes required for majors in the department. Recruitment and assessment procedures were approved by the university's institutional review board.

To be eligible, participants had to be or have been in a serious romantic relationship at some time, either past or 
present. The majority of the participants identified themselves as European Americans (82\%) and most were in their late teens and early twenties $(M=21.9$ years). The average length of relationship of the targeted relationship was 24 months. Of the eight possible categories of relationship status presented in the demographic questionnaire, each category received at least one response. However, because of the low frequencies in some categories, the original categories were collapsed into three: currently married or remarried $(12 \%$, Status $=1)$, single in a current serious relationship $(52 \%$, Status $=2)$, and currently single and in a serious relationship previously, but not at present $(37 \%$, Status $=3)$. Status 2 included participants who were divorced and in a current serious relationship, single and living together, or never married and in a current serious dating relationship. Status 3 included participants who were divorced and dating previously (not presently), divorced and had not been seriously dating since the divorce, or never married and seriously dating previously (not presently). Potential participants who were not and had never been in a serious relationship were excluded from the sample.

\subsection{Measures}

\subsubsection{Attachment Style Prototypes [3]}

The ASP consists of three paragraphs describing current adult attachment styles: Secure, Avoidant, and Anxious/Ambivalent. Participants were asked to choose the paragraph that best described their feelings of comfort in romantic relationships. Distributions of the three attachment styles assessed by the Hazan and Shaver scale are fairly consistent across college populations. Hazan and Shaver reported the frequency for Secure at 56\%, Avoidant at 23\%, and Anxious/Ambivalent at $20 \%$. The reliability of the ASP has been demonstrated by the similarity of results in terms of distribution of attachment styles obtained internationally and across many research studies involving college students and others in Australia, the US, Israel, and China [19-22]. Adequate construct validity has been demonstrated by the relationships between attachment style and attachment history and/or beliefs about self and others [3,6], and by the ability of the ASP classification to predict criterion variables.

\subsubsection{Experiences in Close Relationships [ECR, 8]}

Based on the Bartholomew and Horowitz model [7], the ECR consists of two 18-item scales, Avoidance and Anxiety. The Avoidance scale assesses levels of avoidance of intimacy, discomfort with closeness, and self-reliance. The Anxiety scale assesses jealousy, fear of abandonment, and fear of rejection. Participants in the present study were asked to indicate how they felt in their current romantic relationship, or how they felt in their most significant previous relationship if they were not currently involved romantically. When answering the ECR and the conflict resolution questionnaire, the participants were asked to focus on the same significant romantic relationship they had chosen to focus on in the demographic section.

Each item on the ECR is answered on a 7-point Likert scale ranging from " 1 " (disagree strongly) to "7" (agree strongly), with a middle score of " 4 " (neutral/mixed). The measure has shown high internal consistency with a Cronbach's alpha of .94 for Avoidance and .91 for Anxiety (Brennan, Clark, \& Shaver, 1998). In the current sample, the alpha was .94 for Avoidance and .90 for Anxiety. Good convergent validity has been demonstrated by high correlations between the Avoidance dimension and a large number of other scales measuring avoidance and discomfort with closeness (Brennan, Clark, \& Shaver, 1998). The Anxiety scale correlates highly with a large number of other scales measuring anxiety and preoccupation with attachment, jealousy, and fear of rejection (see Brennan, Clark, \& Shaver, 1998, for details). Although uncorrelated in the original report, Anxiety and Avoidance were moderately correlated in this sample, $r(448)=.25, p<.001$.

\subsubsection{The Rahim Organizational Conflict Inventory-II (ROCI-II, [23]).}

The ROCI-II was used to assess conflict resolution behaviors in romantic relationships. Styles of handling interpersonal conflict are conceptualized along two dimensions, the attempt to satisfy the respondent's own concerns (high or low) and the attempt to satisfy the concerns of others (high or low). The combination of the two dimensions results in five conflict resolution styles [23], Integrating (high concern for self, high concern for others), Dominating (high on self, low on others), Obliging (low on self, high on others), Avoiding (low on self, low on others), and Compromising (medium on self, medium on others).

In the present study, items from the ROCI-II were subjected to a factor analysis that yielded five factors matching Rahim's categories of Integrating, Avoiding Conflict, Dominating, Obliging, and Compromising. Each factor had an eigenvalue above 1.0, and only items with factor loadings greater than an absolute value of .40 were included in computing a score for each scale. The five scale scores were computed using the raw scores for items that loaded at least .40 on the corresponding factor. The three conflict resolution scales addressing more positive styles were significantly and positively correlated-Obliging-Integrating, $\quad r \quad$ (448) = .442; Obliging-Compromising, $r$ (448) $\quad r \quad .477$; Compromising-Integrating, $r(448)=.614, p \mathrm{~s}<.001-$ as were the two more negative styles, Avoiding Conflict-Dominating, $r(448)=.198, r(448)=.442$. However, as might be expected, Avoiding Conflict was also positively correlated with Obliging, $r(448)=.183, r(448)$ $=.442, p \mathrm{~s}<.001$.

The ROCI-II has adequate test-retest reliability, with reported reliabilities ranging from .60 for Compromising to .83 for Integrating. Internal consistency reliability estimates are also satisfactory, with Cronbach alphas ranging from .72 to .77 . The reliabilities in the current sample for the conflict resolution behaviors of Integrating, Avoiding 
Conflict, Dominating, Obliging, and Compromising were $.90, .85, .81, .81$, and .74 , respectively.

\section{Results}

\subsection{Distribution of Attachment Style}

\subsubsection{Four-category based on ECR}

A cluster analysis (k-means procedure) was performed using the two attachment dimensions, Anxiety and Avoidance, of the ECR to define four clusters. The number of clusters was restricted to remain consistent with the four-category model of Brennan, Clark, and Shaver [8]. The four clusters fit the model with groups of Secure (low on Anxiety and Avoidance), Fearful (high on Anxiety and Avoidance), Dismissing (low on Anxiety and high on Avoidance), and Preoccupied (high on Anxiety and low on Avoidance) participants (Figure 1).

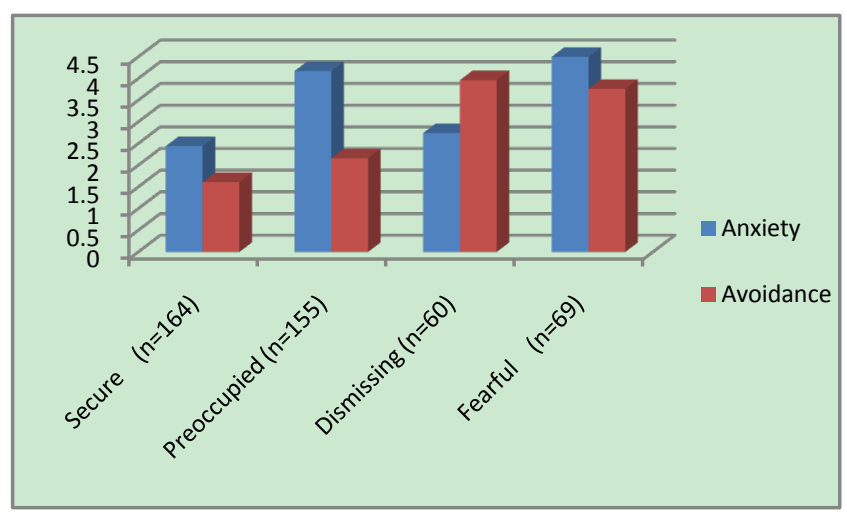

Figure 1. Mean ECR Scores for Four Cluster

\subsubsection{Distribution of 3- and 4-category classifications}

Table 1 shows the distribution of ECR versus ASP attachment categories. The distribution of attachment style categories assessed by the four-category and three-category measures (Table 1) differed significantly, $\chi^{2}(6)=146.19, p$ $<.001$. While the category names vary between the ASP and ECR, three of the categories in each are drawn from the work of Bowlby [12], Ainsworth [24], and George, Kaplan, and Main [2] and are descriptively quite parallel: ASP Secure-ECR Secure, ASP Avoidant-ECR Dismissing, and ASP Anxious/Ambivalent-ECR Preoccupied.

Avoidant categories were shifted into Preoccupied and Fearful ECR categories (28.0\% each), leaving less than a third in the ECR Dismissing category. Participants classified as ASP Anxious/Avoidant were almost equally divided into the ECR Preoccupied (56.1\%) and Fearful (41.5\%) categories. No individual classified as ASP Anxious/Ambivalent was classified as Secure by ECR, and only one Anxious/Ambivalent was classified as Dismissing by the ECR. That is, adding the Fearful category resulted in the greatest changes in the ASP Avoidant and Anxious/Ambivalent categories. However, there were marked changes in the Secure ASP category as well, primarily with a shift into the ECR Preoccupied category.

\subsubsection{Within Various Groups}

Previous studies suggested that the distribution of attachment style is related to the characteristics of the population studied, such as age, length of relationship, and relationship status (e.g., [25-27]). In the current study, age categories were defined as less than 25 and 25 years and older, length of relationship categories were defined as less than 12 months and 12 months and longer. The frequencies of attachment styles assessed by ASP were compared using $\chi^{2}$-tests for different age, relationship length, and relationship status groups. The frequencies are displayed in Table 2. The distribution of attachment style was related to relationship status but not to age or length of relationship. The percentage of Secure attachment style was higher among participants who were married $(82 \%)$ or in serious relationships $(73 \%)$ at the time the study was conducted, compared to the percentage of Secure reported by Hazan and Shaver ([3], $55 \%)$ and others, and compared to the current data.

As shown in Table 1, less than half $(205 / 433,47.3 \%)$ of the participants were classified in the categories that match between the ASP and the ECR. The major shift in classifying the ASP Secure participants was from ASP Secure into the ECR Preoccupied category (33.2\%). Participants as ASP participants not in a current serious relationship but with a history of a previous serious relationship (41\%). Three $\chi^{2}$-tests also were conducted for the four-category ECR measure. Results indicated that the distribution of attachment style was also affected by relationship status but not by age and length of relationship (Table 3). Participants married or in a current relationship were much more likely to be in the Secure category $(61 \%$ and $48 \%$, respectively) than participants who had a past serious relationship (13\%).

\subsubsection{Comparison to Distributions of Brennan, Clark, and Shaver [8] and Hazan\& Shaver [3]}

The ECR distribution was significantly different than that reported by Brennan, Clark, and Shaver (Table 2), $\chi^{2}(3)=$ $12.94, p<.001$. The present sample had fewer than expected participants categorized as Dismissing or Fearful and more categorized as Secure or Preoccupied. The ASP distribution also differed significantly from that of Hazan and Shaver. More of the current participants were classified as Avoidant and fewer were classified as Anxious/Ambivalent, $\chi^{2}(2)=$ $19.75, p<.001$. 
Table 1. Relationships Between the Four-Category and Three-Category Attachment Styles

\begin{tabular}{|c|c|c|c|c|c|c|}
\hline \multirow{2}{*}{$\begin{array}{l}\text { Four-Category } \\
\qquad(\text { ECR })\end{array}$} & \multicolumn{3}{|c|}{$\begin{array}{c}\text { Three-Category (ASP) } \\
\text { (\% in ASP Category Matching ECR Category) }\end{array}$} & \multirow[t]{2}{*}{ Total } & \multirow{2}{*}{$\begin{array}{l}\% \text { in } \\
\text { ECR }\end{array}$} & \multirow{2}{*}{$\begin{array}{l}\% \text { in Brennan } \\
\text { et al., } 1998\end{array}$} \\
\hline & Secure & Avoidant & Anxious/Ambivalent & & & \\
\hline Secure & $145(54.1 \%)$ & 17 & 0 & 162 & $37.4 \%$ & $30.4 \%$ \\
\hline Dismissing & 19 & $37(29.6 \%)$ & 1 & 57 & $13.2 \%$ & $20.8 \%$ \\
\hline Preoccupied & 89 & 35 & $23(56.1 \%)$ & 147 & $33.9 \%$ & $24.4 \%$ \\
\hline Fearful & 15 & 35 & 17 & 67 & $15.5 \%$ & $24.4 \%$ \\
\hline Total & 268 & 125 & 41 & 433 & $100 \%$ & $100 \%$ \\
\hline$\%$ in ASP & $61.9 \%$ & $28.9 \%$ & $9.5 \%$ & $100 \%$ & & \\
\hline $\begin{array}{l}\text { \% in Hazan\& } \\
\text { Shaver, } 1987\end{array}$ & $56 \%$ & $23 \%$ & $20 \%$ & $100 \%$ & & \\
\hline
\end{tabular}

Note: The first three pairs of terms are often used interchangeably

Table 2. Distribution of Three-Category (ASP) and Four-Category (ECR) Attachment Styles by Age, Length of Relationship, and Relationship Status

\begin{tabular}{|c|c|c|c|c|c|c|}
\hline Three-Category (ASP) & Secure & Avoidant & Anxious/Ambivalent & & $\chi^{2}$ & $p$ \\
\hline \multicolumn{7}{|l|}{ Age } \\
\hline $\begin{array}{l}<25 \\
\geq 25\end{array}$ & $\begin{array}{c}220(60 \%) \\
41(76 \%)\end{array}$ & $\begin{array}{c}111(30 \%) \\
10(19 \%)\end{array}$ & $\begin{array}{c}38(10 \%) \\
3(6 \%)\end{array}$ & & 5.33 & .07 \\
\hline \multicolumn{7}{|l|}{ Relationship Length } \\
\hline $\begin{array}{l}<12 \mathrm{mo} \\
\geq 12 \mathrm{mo}\end{array}$ & $\begin{array}{c}86(61 \%) \\
176(63 \%)\end{array}$ & $\begin{array}{l}42(30 \%) \\
78(28 \%)\end{array}$ & $\begin{array}{c}12(9 \%) \\
27(10 \%)\end{array}$ & & 0.30 & .86 \\
\hline \multicolumn{7}{|l|}{ Relationship Status } \\
\hline $\begin{array}{c}\text { Married } \\
\text { Current } \\
\text { Previous }\end{array}$ & $\begin{array}{c}41(82 \%) \\
163(73 \%) \\
64(41 \%) \\
\end{array}$ & $\begin{array}{c}8(16 \%) \\
51(23 \%) \\
63(40 \%) \\
\end{array}$ & $\begin{array}{c}1(2 \%) \\
9(4 \%) \\
30(19 \%)\end{array}$ & & 57.43 & .001 \\
\hline Four-Category (ECR) & Secure & Dismissing & Preoccupied & Fearful & $\chi^{2}$ & $p$ \\
\hline \multicolumn{7}{|l|}{ Age } \\
\hline $\begin{array}{l}<25 \\
\geq 25\end{array}$ & $\begin{array}{c}136(36 \%) \\
24(44 \%)\end{array}$ & $\begin{array}{c}54(14 \%) \\
6(11 \%)\end{array}$ & $\begin{array}{c}133(35 \%) \\
15(27 \%)\end{array}$ & $\begin{array}{l}59(15 \%) \\
10(18 \%)\end{array}$ & 2.25 & .52 \\
\hline \multicolumn{7}{|l|}{ Relationship Length } \\
\hline $\begin{array}{l}<12 \mathrm{mo} \\
\geq 12 \mathrm{mo}\end{array}$ & $\begin{array}{l}46(32 \%) \\
113(39 \%)\end{array}$ & $\begin{array}{l}25(18 \%) \\
33(11 \%)\end{array}$ & $\begin{array}{l}46(32 \%) \\
107(37 \%)\end{array}$ & $\begin{array}{l}26(18 \%) \\
40(14 \%)\end{array}$ & .70 & .13 \\
\hline \multicolumn{7}{|l|}{ Relationship Status } \\
\hline $\begin{array}{c}\text { Married } \\
\text { Current } \\
\text { Previous }\end{array}$ & $\begin{array}{c}31(61 \%) \\
111(48 \%) \\
22(13 \%)\end{array}$ & $\begin{array}{c}3(6 \%) \\
23(10 \%) \\
34(21 \%)\end{array}$ & $\begin{array}{l}15(29 \%) \\
80(35 \%) \\
59(36 \%)\end{array}$ & $\begin{array}{c}2(4 \%) \\
16(7 \%) \\
49(30 \%)\end{array}$ & 89.80 & .001 \\
\hline
\end{tabular}

\subsection{Relationships between the Two Measures}

To examine the effect of attachment style (as categorized by ASP) on the two attachment dimensions assessed by the ECR, two multiple linear regression analyses were performed. In the first regression, dummy variables for ASP Avoidant ( 1 = "Avoidant," $0=$ "Not Avoidant) and for ASP Anxious/Ambivalent ( 1 = "Anxious/Ambivalent," $0=$ "Not Anxious/Ambivalent) were created. These two dummy variables served as the predictor variables, and the ECR attachment dimension of Anxiety as the outcome variable.

In the second regression, the same dummy variables served as the predictor variables, and the ECR attachment dimension of Avoidance as the outcome variable. For both regression models, there was a significant overall effect of ASP attachment style on the specified ECR attachment dimension, Avoidance, $F(2,445)=86.84, p<.001$; Anxiety, $F(2,445)=59.85, p<.001$. For the ECR dimension of 
Avoidance, the ASP attachment style explained $28 \%$ of the variance. For the ECR dimension of Anxiety, the ASP attachment style explained $21 \%$ of the variance. Each of the dummy variables representing ASP Avoidant and Anxious/Ambivalent was a significant predictor of both ECR Avoidance and Anxiety:ECR Avoidance: ASP Avoidant, $t(446)=13.12, p<.001, \quad$ ASP Anxious/Ambivalent, $t(446)=3.75, p<.001$; ECR Anxiety: ASP Avoidant, $t(446)=5.40, p<.001$, ASP Anxious/Ambivalent, $t(446)=10.39, p<.001$.

A MANOVA with ASP category $(1=$ Secure, $2=$ Avoidant, $3=$ Anxious/Ambivalent) as the independent variable and ECR Anxiety and Avoidance scores as the dependent variables was significant, Wilks' Lambda $=.573$,

$F(4,858)=68.83, p<.001$, partial eta squared $=.243$. Univariate ANOVAs were significant for both Anxiety and Avoidance. Tukey's HSD test indicated significant differences between each of the three groups. ASP Avoidant participants scored highest on the ECR Avoidance scale, followed by ASP Anxious/Ambivalent participants and, finally, ASP Secure participants. ASP Anxious/Ambivalent participants scored highest on the ECR Anxiety scale, followed by ASP Avoidant participants and, finally, ASP Secure participants.

\subsection{Two Measures as Predictors of the ROCI-II Scales}

First, five multiple linear regression analyses were performed using the two ASP category dummy variables for Avoidant and Anxious/Ambivalent styles as the predictor variables and each of the five ROCI-II conflict resolution behavior scales as the dependent variable. Overall, ASP attachment style was a significant predictor of the conflict resolution behaviors of Integrating, Obliging, and Compromising at the .001 level, but failed to predict Avoiding and Dominating (Table 3). The two dummy variables for Avoidant and Anxious/Ambivalent styles predicted $11.4 \%$ of the variance in Integrating, 3.9\% for obliging, and $4.0 \%$ for Compromising. For the three ROCI-II styles that were significantly predicted, the beta values were negative for the dummy variable representing ASP Avoidant style. All beta values were significant; the higher the score for Integrating, Obliging, or compromising, the less likely the participant was to be classified by the ASP as Avoidant. When the participant's ASP attachment style was Anxious/Ambivalent, only the beta for Integrating was negative and significant. The greater the score for Integrating, the less likely the participant was to be categorized as Anxious/Ambivalent.

Table 3. Results of Multiple Regressions on Conflict Resolution Scales $\underline{n}=448$ ).

\begin{tabular}{|c|c|c|c|c|c|}
\hline \multicolumn{6}{|l|}{ ROCI-II } \\
\hline & Integrating & Avoiding & Dominating & Obliging & Compromising \\
\hline \multicolumn{6}{|l|}{ ASP } \\
\hline Avoidant & -.340 & .161 & .157 & -.205 & -.207 \\
\hline $\begin{array}{c}\text { Beta } \\
t\end{array}$ & $-7.353^{*}$ & $3.323 *$ & $3.223 *$ & $-4.254 *$ & $-4.305^{*}$ \\
\hline \multicolumn{6}{|l|}{ Anxious/ } \\
\hline Ambivalent & -.157 & .085 & .081 & .013 & .018 \\
\hline $\begin{array}{c}\text { Beta } \\
t\end{array}$ & $-3.403 *$ & 1.752 & 1.662 & .273 & .383 \\
\hline & $28.9^{*}$ & 6.12 & 5.72 & $9.74 *$ & $10.10^{*}$ \\
\hline $\begin{array}{l}F \\
R^{2}\end{array}$ & .114 & .023 & .021 & .039 & .040 \\
\hline \multicolumn{6}{|l|}{ ECR } \\
\hline \multicolumn{6}{|l|}{ Avoidance } \\
\hline Beta & -.439 & .337 & .166 & -.275 & -.271 \\
\hline$t$ & $-9.832 *$ & $7.429^{*}$ & $3.620^{*}$ & $-5.942 *$ & $-5.747 *$ \\
\hline \multicolumn{6}{|l|}{ Anxiety } \\
\hline Beta & .063 & .132 & .282 & .304 & .217 \\
\hline$t$ & 1.405 & 2.922 & $6.137^{*}$ & $6.558^{*}$ & $4.602 *$ \\
\hline$F$ & $49.500 *$ & $41.749^{*}$ & $34.826^{*}$ & $30.371 *$ & $21.190 *$ \\
\hline$R^{2}$ & .177 & .153 & .130 & .115 & .082 \\
\hline
\end{tabular}

Note: ${ }^{*} p<0.001$ 
Second, five multiple regressions were performed with ECR Avoidance and Anxiety scores as the predictor variables, and each of the ROCI-II scales as outcome variables. Overall, attachment dimensions were significant predictors of all five ROCI-II variables $(p<.001)$ (Table 3 ). Using .001 as a criterion, the ECR dimension of Avoidance successfully predicted for all five ROCI-II scores, while the dimension of ECR Anxiety predicted three of the scales, but failed to predict the conflict resolution behaviors of Integrating and Conflict Avoidance. As would be predicted, the ECR Avoidance scale betas were negative for Integrating, Obliging, and Compromising and positive for Conflict Avoidance and Dominating. Beta values for the ECR Anxiety scale were positive for Dominating, Obliging, and Compromising. For each ROCI-II scale, ECR attachment dimensions explained more variance than did ASP attachment style (Table 4).

Table 4. Summary of Tukey HSD Comparisons

\begin{tabular}{cccccc}
\hline $\begin{array}{c}\text { ROCI-II } \\
\text { Attachment } \\
\text { Category } \\
\text { ASP }\end{array}$ & Integrating Obliging & Compromisin & Dominatin & \\
Secure & B & B & B & A & A \\
Anxious/ & A & B & B & AB & AB \\
Ambivalent & & & & & \\
Avoidant & A & A & A & B & B \\
ECR & & & & & \\
Secure & C & C & B & A & A \\
Preoccupied & B & BC & B & B & A \\
Dismissing & A & A & A & B & B \\
Fearful & A & B & A & B & B \\
\hline
\end{tabular}

Note: Within each attachment scale, "A"— category with lowest score, "B"- category with next highest score, "C"-category with highest score on scale. "AB" - not significantly different from group A or group $\mathrm{B}$, "BC" - not significantly different from group $\mathrm{B}$ or group $\mathrm{C}$.

\subsection{Using Categories to Predict ROCI-II Scores}

Although the ECR scales were better predictors of the ROCI-II scales, participants in the three ASP categories did differ significantly in their ROCI-II scores. A MANOVA was conducted to examine ASP category differences in the five ROCI-II scales, and an overall effect of category was found, Wilks' Lambda $=.837, F(10,852)=79.40, p<.001$, partial eta squared $=.085$. The univariate ANOVAs were all significant at the .001 level. The results of the Tukey's HSD tests are summarized in. With the exception of Integrating, there was no significant difference in ROCI-II scale scores between Secure and Anxious/Ambivalent participants' scores. However, significant differences between Secure and Avoidant participants were present for all five ROCI-II scales.

As a comparison, a second MANOVA was conducted to examine ECR categories in relation to ROCI-II scales. An overall effect of category was found, Wilks' Lambda $=.623$, $F(15,1215)=15.13, p<.001$, partial eta squared $=.146$. The univariate ANOVAs were all significant at the .001 level. Tukey's HSD tests (Table 4) indicated significant differences between Secure participants' scores and those of Preoccupied participants, on Integrating and Dominating, but not on the other three scales. Secure participants' scores did differ from both Fearful and Dismissing participants. Dismissing and Fearful participants differed only on the Obliging scale. Neither the ASP nor the ECR categories were able to identify differences between Secure and ASP Anxious/Ambivalent or ECR Preoccupied participants but did show differences between the Secure and ASP Avoidant and ECR Dismissing or Fearful participants. In short, Anxious/Ambivalent or Preoccupied participants were most similar to the ROCI-II to Secure participants in their responses when either the ASP or ECR categories were used, and Fearful and Dismissing participants were most similar when only the ECR categories were considered.

\section{Discussion}

To gain a better understanding of the existing self-report adult attachment measures, the study compared the ASP with the ECR on distribution of attachment styles and their ability to predict conflict resolution behaviors. It also examined the relations between the two measures. The two measures were consistent and related in meaningful ways; however, they also differed in the ability to identify certain attachment characteristics. In addition, ECR, along with its more comprehensive 4-category classification system, appeared to be a better predictor for relationship functioning.

\subsection{Comparison between Three and Four-category Measures}

The cluster analysis using the ECR Anxiety and Avoidance scales produced groups with mean scores that matched the expected means of the four categories (Figure 1). Most of the 433 participants fell into either the Secure or the Preoccupied category on the ASP (Table 1). Three of the categories in each measure are conceptually quite similar: Secure-Secure, Avoidant-Dismissing, and Anxious/Ambivalent-Preoccupied. These terms are often used interchangeably in the literature; however, it is clear that the ASP and ECR are quite different. Considering the whole sample, there were considerable shifts among categories. It is not just that the fourth category, Fearful attachment, resulted in shifts, particularly from the ASP Avoidant and Anxious/Ambivalent categories. Rather, almost $30 \%$ of participants classified as ASP Avoidant were reclassified into the ECR Preoccupied category, and 33\% of participants categorized as ASP Secure were reclassified as ECR Preoccupied. Certainly, no equivalency of measurement can be assumed in comparing the results of 
studies that used the ASP with those that used the ECR.

A closer examination of the three paragraphs of ASP reveals that the paragraphs describing Secure and Anxious/Ambivalent both contain elements of wanting to be closer to others. It is possible that some individuals with Anxious/Ambivalent characteristics deny their urge to merge with others by choosing to present a more socially acceptable image. This choice could be made consciously as a result of social desirability or without awareness. Given that the proportion of attachment styles is consistent, within limits, across college student samples in various cultures, it is reasonable to speculate that a consistent proportion of ASP Anxious/Ambivalent individuals report themselves as Secure. However, it is not clear what types of individuals tend to be attracted by the description of ASP Secure attachment style. That description does tend to reflect society's view of a good partner in a relationship, and might be expected to have persons with all four ECR types selecting it if the ECR is accepted as the standard (i.e., the high rate of ASP "false positives" of $45.9 \%$ ).

The situation is even more complex when the ASP Avoidant participants responded to the ECR scales. Seventy percent of ASP Avoidant participants were reclassified by the ECR - twice as many into the Fearful or Preoccupied category as into the Secure category. Of the $44 \%$ who shifted from the ASP Anxious-Ambivalent category, all but one was reclassified as Fearful. While it is difficult to claim primacy for the ECR, it does not seem that ASP is sensitive and powerful enough to distinguish among attachment categories. This failure to distinguish may be the result of overlapping constructs among the three descriptions in the ASP. ECR, on the other hand, is a multi-itemed instrument, and it can potentially reduce the chance of inaccuracy and response bias due to factors such as social desirability.

When divided by age, relationship length, or relationship status, the percentage of participants categorized as Secure by the ASP was always higher than in the other two ASP categories; however, the difference was only $1 \%$ between Secure and Avoidant classifications in the group of participants not in a current relationship. This result suggests that those who had had previous relationships may have had substantial difficulty maintaining their relationships because of their greater likelihood of having an Avoidant or Anxious/Ambivalent approach to relationships.

The pattern of having a majority of Secure participants in the sample vanished when the ECR was considered. This was largely the effect of a higher percentage of participants categorized as Preoccupied (27\%-37\%) across age, relationship length, and relationship status, when compared to the ASP Anxious/Ambivalent percentage (6\%-19\%). As was true for the ASP Secure category, those in a previous, but not current, relationship were least likely to score in the Secure category. Compared to married participants, they were five times less likely to be categorized as secure, three times more likely to be categorized as Dismissing, equally as likely to be categorized as preoccupied, and seven times more likely to be categories as Fearful. The percentage distribution of participants in a current relationship, but not married or remarried, was similar to that of married or remarried participants.

It is reasonable to argue that attachment style and relationships interact. People with Secure attachment, however defined, are better able to maintain their relationships and thus have a better chance transitioning into marriage. On the other hand, marital relationships may create an environment for the development and maintenance of a secure attachment style. A person with an insecure attachment style as indicated by either the ASP or ECR, however, would be expected to be less able to maintain a relationship successfully. The prior loss of a serious relationship would be expected to increase feelings of insecurity (e.g., the anxiety of the Anxious/Ambivalent or Preoccupied person), fear of future injury or abandonment (Avoidant or Fearful persons), and unwillingness to enter into another serious relationship (Avoidant or Dismissing or Fearful person). Following the same line of thought, the results do suggest that both measures capture certain attachment aspects that are associated with the presence of a serious romantic partner, someone who can serve as an adult romantic attachment figure. Testing a measure across various relationship contexts, as suggested by Sperling and Berman [28], may help clarify exactly what each of these instruments measures.

\subsection{Comparison between Three-Category and Two Dimensions of the ECR}

The two measures relate in meaningful ways even though they seem to be accessing different aspects of relationships. Attachment style assessed by ASP had a significant relationship with the two ECR attachment dimensions of Anxiety and Avoidance, explaining $21 \%$ and $28 \%$ of the variance, respectively. Individuals in the three ASP attachment groups scored significantly differently on the two dimensions. ASP Avoidant participants scored highest on the ECR Avoidance scale, with Anxious/Ambivalent participants scoring significantly lower, and Secure participants scoring significantly lower than both. On the ECR Anxiety scale, Anxious/Ambivalent participants scored highest, followed by Avoidant and Secure. All three groups differed significantly on the Anxiety scale. Thus, despite differences in conceptualization, there is an overlap between the measures. This finding provides an explanation of the positive relation between the attachment styles they assess and criterion variables in romantic relationships.

Basically, the two sets of 5 multiple linear regressions pitted the ASP categories of Avoidant and Anxious/Ambivalent (each dummy coded as 0 or 1 ) against the continuous ECR Anxiety and Avoidance scales. Overall, the attachment dimensions predicted all five conflict resolution behaviors while the attachment styles together predicted only three of five. Further, the attachment dimensions also explained a greater percentage of the variance in the ROCI-II variables. Attachment dimensions 
appeared to be better predictors of conflict resolution behaviors; this may be due to two reasons. First, although instructed to focus on the significant romantic relationship throughout their participation, the participants might have shifted their thoughts and feelings toward relationships in general because the ASP describes the three attachment styles in very general terms. Second, ECR and ROCI-II share more similarities in conceptualization. They both are informed by two dimensions based on the perception of self and the other. This supports the notion that attention should be paid to the conceptualization of outcome variables in relation to the attachment conceptualization [29].

Individually, the dimension of Avoidance successfully predicted all ROCI-II variables, while the dimension of Anxiety predicted three of five. For the three attachment styles assessed by the ASP, individuals classified as Avoidant scored differently from those classified as Secure on all five criterion variables. However, individuals classified as Anxious/Ambivalent failed to score differently from those in Secure on four out of five criterion variables. A similar problem was found with the ECR categories-Preoccupied participants did not differ from Secure participants with the exception of one scale, and Fearful and Dismissing participants also differed on only a single scale. This indicates that the categorical approach is unable to discriminate well among pairs of categories when using an instrument like the ROCI-II. This result shows that ECR, when the scales are used as continuous variables, is a more sensitive and powerful instrument in the relationship context examined.

\section{Conclusions}

The important issue continues to remain in determining how attachment should be conceptualized, categorically or incrementally different [15]. Researchers such as Fraley and Waller [14] have made a strong argument that adult attachment is best described as falling along several dimensional measures. Researchers also favor dimensional measures for their reliability, sensitivity, and lessened response bias. Avoidance and Anxiety have been considered as the two primary dimensions underling adult attachment [30]. The results of this study further indicate that dimensional measures have several advantages over categorical ones. This does not necessarily mean, however, that categorical adult attachment measures are less informative, or even be abandoned. The data in Table 4 lead to potentially fruitful speculations about why Secure and Anxious/Ambivalent persons are so similar and how they differ, as is true for Fearful and Dismissing persons. Categorical measures provide a broad description of the archetype of the category. Bowlby and Ainsworth's categories have provided rich information on individual variations, in type, not in degree, and have provided the impetus for a large body of research, theory development, and clinical application. It makes sense that both categorical and dimensional measures should co-exist, just like interview and self-report measures should. Testing the measures in various relationship contexts will help determine what they measure, when they should be used, and in what context.

\section{REFERENCES}

[1] W. H.Berman,M. B. Sperling. The structure and function of adult attachment. In M. Sperling, \& W. Berman (Eds.), Attachment in adults: Clinical and developmental perspectives (pp. 3-28). New York: Guilford Press, 1994.

[2] C, George, N,Kaplan, M. Main, M.Adult Attachment Interview. Unpublished Manuscript, University of California, Berkeley, 1996.

[3] C. Hazan, P. Shaver. Romantic love conceptualized as an attachment process. Journal of Personality and Social Psychology, Vol.52, 511-524, 1987.

[4] K. Bartholomew, P. Shaver. Methods of assessing adult attachment: Do they converge? In J. A. Simpson, \& W. S. Rholes (Eds.), Attachment Theory and Close Relationships. New York: The Guilford Press, 1998.

[5] K. Bartholomew. Avoidance of intimacy: An attachment perspective. Journal of Social and Personal Relationships, Vol.7, 147-178, 1990.

[6] N. Collins, S. Read, S. Adult attachment, working models, and relationship quality in dating couples.Journal of Personality and Social Psychology, Vol.58, 644-663, 1990.

[7] K. Bartholomew,L. Horowitz. Attachment styles among young adults: A test of a four-category model. Journal of Personality and Social Psychology, Vol.61, 226-244, 1991.

[8] L. Brennan, C. Clark, P. Shaver. (1998). Self-report measurement of adult attachment. In J. A. Simpson, \& W. S. Rholes (Eds.), Attachment Theory and Close Relationships. New York: The Guilford Press, 1998.

[9] N. Collins. Working models of attachment: Implications for explanation, emotion, and behavior. Journal of Personality and Social Psychology, Vol.71, 810-832, 1996.

[10] J. Simpson. (1990). Influence of attachment style on romantic relationships.Journal of Personality and Social Psychology, Vol.59, 971-980, 1990.

[11] J. Feeney, P. Noller, V.Callan. Attachment style, communication and satisfaction in the early years of marriage.Advances in Personal Relationships, Vol.5, 269-308, 1994.

[12] C. Hazan, P. Shaver.Adult Attachment Questionnaire.Unpublished scale, University of Denver, 1988.

[13] L. Bowlby. Attachment and Loss: Vol. 2.Separation, Anxiety, and Anger. New York: Basic Books, 1973.

[14] R. C. Fraley, N. G. Waller. Adult attachment patterns: A test of the typological model. In J. A. Simpson, \& W. S. Rholes (Eds.), Attachment Theory and Close Relationships. New York: The Guilford Press, 1998. 
[15] J. Crowell, C. Fraley, P. Shaver. Measurement of individual differences in adolescent and adult attachment. In J. Cassidy \& P. Shaver (Eds.), Hankbook of Attachment: Theory, Research, and Clinical Applications. New York: The Guilford Press, 2008.

[16] P. Shaver, M. Mikulincer. Dialogue on adult attachment: Diversity and integration. Attachment \& Human Development, Vol.4, 243-257, 2002.

[17] L. McWilliams, B. S. effrey. Associations between adult attachment ratings and health conditions: Evidence from the National Comorbidity Survey Replication. Health Psychology, Vol. 29, No.4, 446-453, 2010.

[18] W. Roger Mills-Koonce, K. Appleyard, M. Barnett, M. Deng, M. Putallaz, M. Cox. Adult attachment style and stress as risk factors for early maternal sensitivity and negativity. Infant Mental Health Journal, Vol.32, 277-285, 2011.

[19] J. Feeney, P. Noller.Attachment style as a predictor of adult romantic relationships. Journal of Personality and Social Psychology, Vol.58, 281-291, 1990.

[20] J. P. Keelan, K. L. Dion, K. K. Dion. Attachment style and heterosexual relationships among young adults: A short term panel study. Journal of Social and Personal Relationships, Vol.11,201-214, 1994.

[21] M. Mikulincer, O. Nachshon. Attachment style and patterns of self-disclosure. Journal of Personality and Social Psychology, Vol.61,321-331, 1991.

[22] L. Shi. (2010) Adult attachment patterns and their consequences romantic relationships: A comparison between China and the U.S (pp. 259-277). In P. Erdman \& K-M,
$\mathrm{Ng}$ (Eds.), Attachment: Expanding the Cultural Connections. Routledge/Taylor and Francis, 2010.

[23] F. Rahim. A measure of styles of handling interpersonal conflict. Academy of Management Journal, Vol.26,368-376, 1983.

[24] M. D. S. Ainsworth. (1982). Attachment: Retrospect and prospect. In: C. M. Parkes\& J. Stevenson-Hinde (Eds.), The place of Attachment in Human Behavior. New York: Basic Books, 1982

[25] T. Fuller, F. Fincham. Attachment style in married couples: Relation to current marital functioning, stability over time, and method of assessment. Personal Relationships, Vol.2, 17-34, 1995

[26] L. Kirkpatrick, K. Davis, K. Attachment style, gender, and relationship stability: A longitudinal analysis. Journal of Personality and Social Psychology, Vol.66,502-512, 1994.

[27] M. Senchak, K. Leonard, K. Attachment styles and marital adjustment among newlywed couples. Journal of Social and Personal Relationships, Vol.9, 51-64, 1992.

[28] M. B. Sperling, W. H. Berman. An attachment classification of desperate love. Journal of Personality Assessment, Vol.56,45-55, 1991

[29] L. Shi. The association between adult attachment styles and conflict resolution in romantic relationships. The American Journal of Family Therapy, Vol.31, 143-157, 2003.

[30] J. A. Feeney. Attachment-related dynamics: What can we learn from self-reports of avoidance and anxiety? Attachment \& Human Development, Vol.4, 193-200, 2002. 